\title{
FEASIBILITY ASSESSMENT OF SOLAR PROCESS HEAT APPLICATIONS
}

\author{
Christoph Lauterbach, Shahrdad Javid Rad, Bastian Schmitt, Klaus Vajen \\ Kassel University, Institute of Thermal Engineering, Kassel (Germany) \\ www.solar.uni-kassel.de, solar@uni-kassel.de
}

\section{Introduction}

The industrial sector represents a very promising application area for the further spread of solar thermal technology, since the sector accounts for $28 \%$ of the total final energy consumption in Germany and other highly industrialized countries, and $75 \%$ of this final energy consumption is used as thermal energy (Lauterbach et al., 2010). Several industrial sectors and processes were identified as suitable for the application of solar heating systems in potential studies, which have been carried out in the past for different countries or regions. A subtask of IEA SHC Task 33/IV summarized the outcomes of the potential studies performed in different countries all over the world (Vannoni et al., 2008). This summary mainly contains the outcomes regarding suitable industrial sectors and the quantified potential for solar heat in industrial processes. In previous studies, the suitability of industrial processes was mainly judged by their temperature level. As the decision for installing a solar heating system is mainly based on its economic feasibility, the solar heat generation costs have to be considered.

In this paper, the previous potential studies in the field of solar process heat were analyzed regarding suitable processes. Additional industrial processes for solar process heat applications were identified in a potential study for Germany (Lauterbach et al., 2011b). The analysis of industrial processes shows that similar applications for solar process heat exist across several sectors. Therefore, industrial processes are categorized which facilitates the identification of typical "solar process heat applications". The feasibility for a selected solar process heat application is assessed by combining simulation results with a cost analysis of solar heating system using different collector types and conventional heat generation costs in industry. This assessment is done for different regions and also facilitates the choice of a collector type for the selected application. The determination of the annual specific energy yield for applications in industry is performed on the basis of system simulation, using TRNSYS. This results in typical annual specific energy yields for the solar process heat application in dependence of temperature level, location and collector type. The cost for solar heating systems of fossil fuel prices for different sizes of industrial companies are analyzed based on literature and recent demonstration plants in industry and other applications. The annual energy yield, fuel price and costs for solar heating systems are used for the assessment based on the Guideline VDI 6002 (VDI, 2004) of "Association of German Engineers" which provides a methodology for calculating the solar heating costs.

\section{Solar process heat applications}

The analysis of industrial sectors shows, that many processes which seem to be promising for the integration of solar heat exist across several sectors. Additionally, similar processes across all industrial sectors can be categorized into typical applications for solar process heat. The processes displayed in Figure 1 were identified as promising for the integration of solar heat in various studies (Aidonis et al., 2002, Lauterbach et al., 2011b, Müller et al., 2004, Schweiger et al., 2001) as they all take place at low or medium temperatures. They can be categorized in the following three major application.

\section{Heating of fluid streams}

Processes where a cold (or in some cases a preheated) fluid stream has to be heated up to a certain temperature are classified in this application. These processes can be found in nearly all industrial sectors as heating of make-up or boiler feed water, preheating of materials, washing, cleaning and sterilization belong to this application. 


\section{Heating of baths/vessels}

The processes which are classified in this application have in common that a bath or vessel filled with a liquid has to be heated to a certain temperature and/or kept at this temperature during production hours. Like the first application "heating of fluid streams" it can be found in nearly all industrial sectors. Processes like cooking, blanching, pasteurization, degreasing, bleaching and surface treatment in the machinery and equipment sector belong to this application.

\section{Drying}

Although for drying processes a fluid stream has to be heated. However, it is considered separately since there is a possibility to use different components (e.g. air collectors) and system configurations for this application. Figure 1 shows that drying processes can be found in nearly all industrial sectors. Furthermore smoking in the food sector can be assigned to this application as air has to be heated very similar to drying processes.

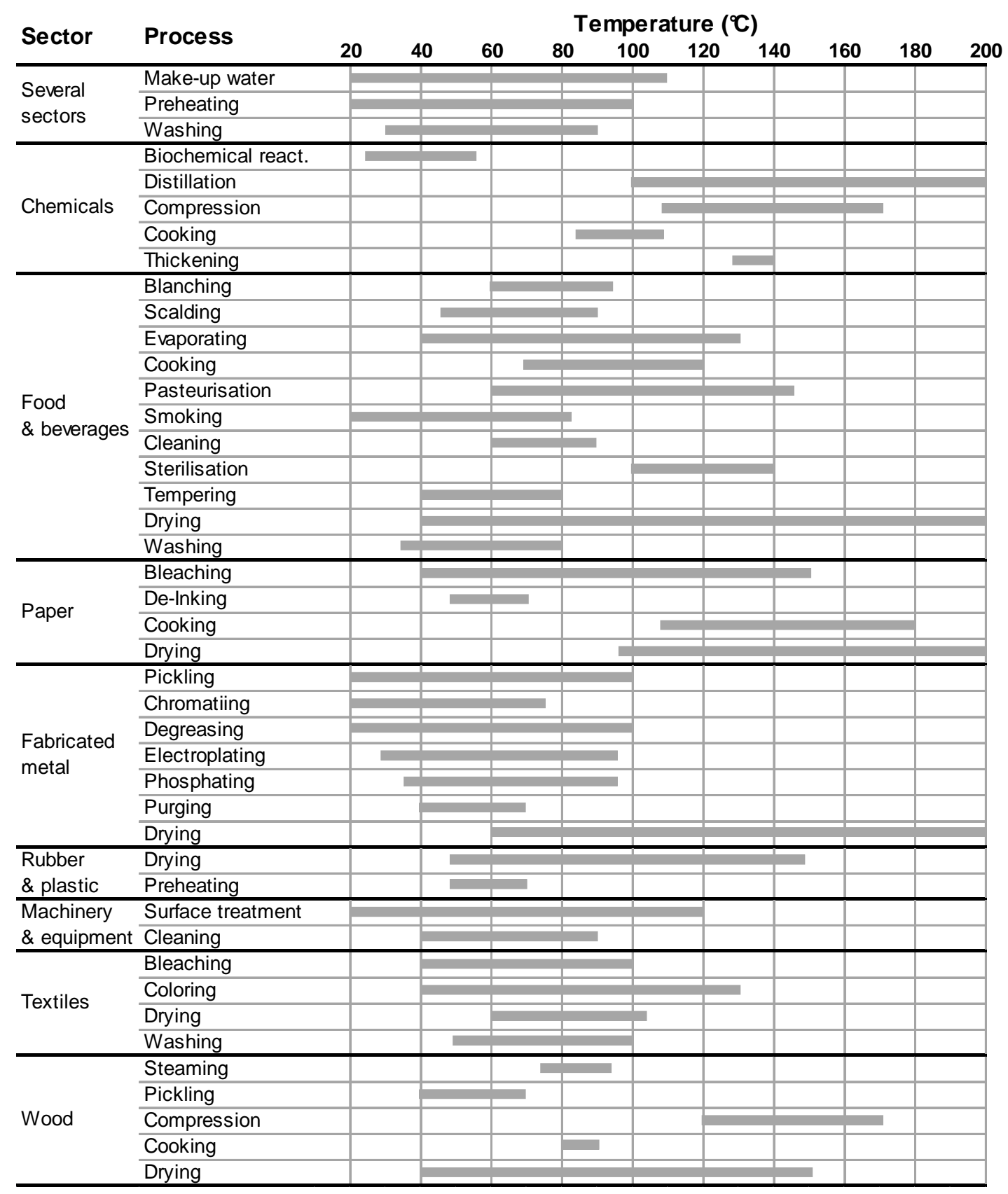

Fig. 1: Promising processes for the integration of solar heat (Aidonis et al., 2002, Lauterbach et al., 2011a, Müller et al., 2004, Schweiger et al., 2001) 
Besides the possibility to integrate solar heat on process level like it is done in most of the above mentioned applications it is possible to integrate a solar heating on heat supply level of an industrial company, as described in (Schmitt et al., 2011). In addition to preheating make-up or boiler feed water the heating of a hot water circuit or direct steam production by a solar heating system are the main applications on supply level. As these applications on supply level require a high temperature which is unfavorable for the feasibility at central European climate conditions, they are not covered in this paper.

To verify the results regarding the importance of the industrial processes displayed in Figure 1 and the classification into "solar process heat applications" results of former studies and working groups were analyzed. Various solar heating systems built in industrial companies in the past were analyzed within "IEA SHC Task 33/IV - Solar Heat for Industrial Processes" of the International Energy Agency. Beside the size of the system and industrial sector of the company, other characteristics of the analyzed systems such as the processes in which the solar heating system was integrated were documented. Of 71 installed solar heating systems 36 or $51 \%$ were used to provide hot water, heat up make-up water or washing processes, which refer to the application "heating of fluid streams". $14 \%$ of the analyzed systems were integrated in processes of the application "heating of baths/vessels", $6 \%$ for drying processes and $29 \%$ for other processes, which do not belong to the industrial sector, most of them being car washing facilities (Task33, 2006). The temperature level needed for an industrial process is crucial for the feasibility assessment, as the annual energy yield of a solar heating system strongly depends on provided temperature. Figure 1 shows the temperature levels of the most promising processes for the integration of solar heat that were identified within several potential studies. Many processes can be found at temperatures below $40{ }^{\circ} \mathrm{C}$, and 40 to $60{ }^{\circ} \mathrm{C}$. Processes within the temperature range of $60 . .100{ }^{\circ} \mathrm{C}$ are of high importance as well. Figure 2 shows the temperatures of processes, which were supplied with solar heat in the past. This also demonstrates the importance of the above mentioned temperature ranges (Task33, 2006).

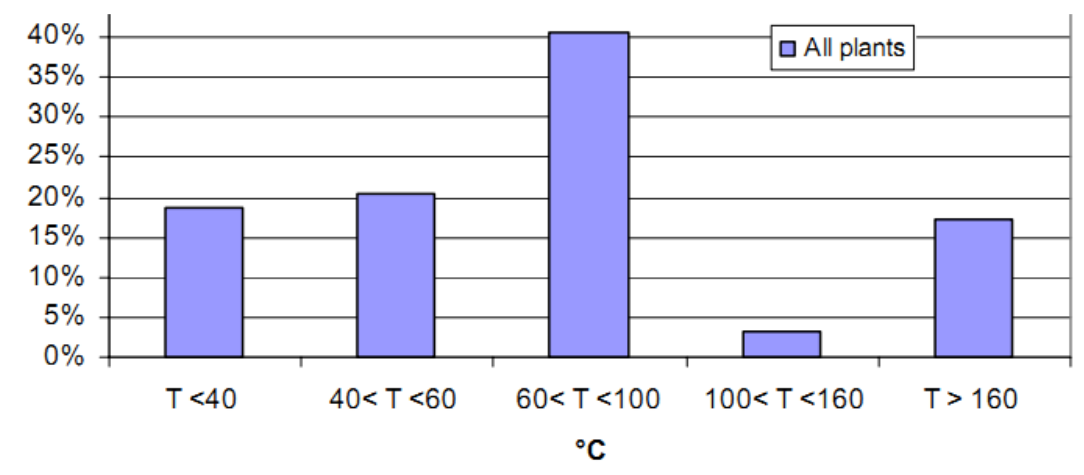

Fig. 2: Temperature level of the supported processes of existing solar heating systems (Task33, 2006)

A short analysis of 90 industrial companies was performed within the European project "Solar Process Heat SO-PRO". Within these screenings suitable processes for the integration of solar heat were identified. Figure 3 shows the identified processes/applications and the distribution of their temperature levels.
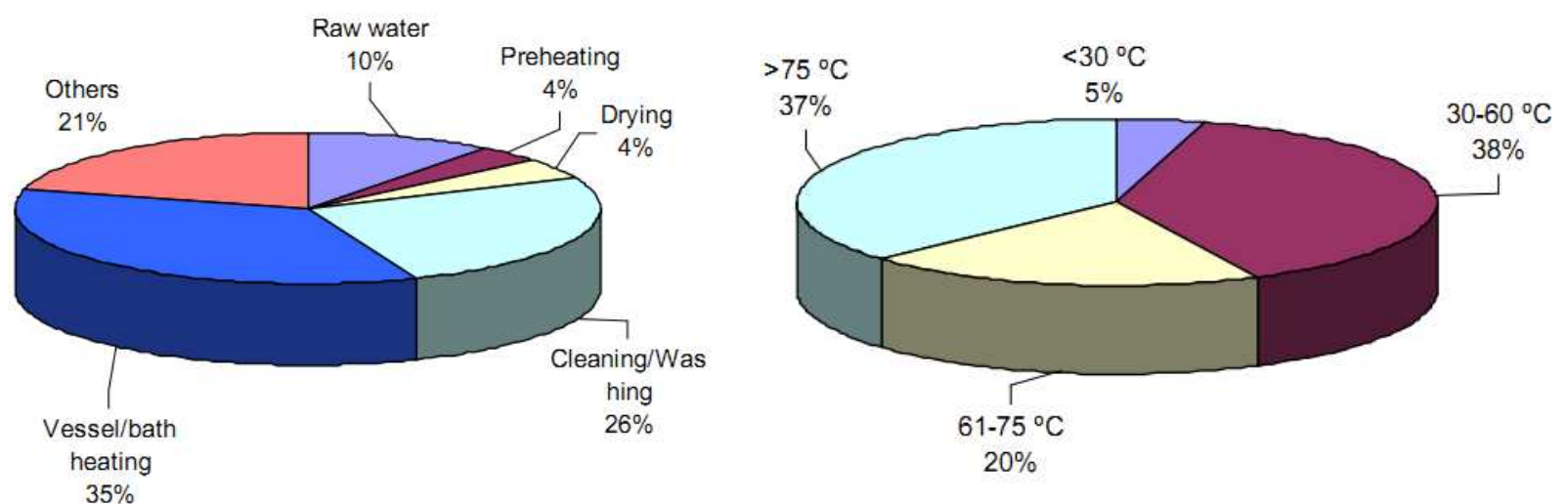

Fig. 3: Promising processes and applications for the integration of solar heat and their temperature level identified within the screening of the SOPRO Procject (SOPRO, 2010) 
Figure 3 contains processes e.g. cleaning/washing as well as applications e.g. vessel/bath heating. The processes cleaning/washing, raw water (which refers to the preheating of make-up water) and preheating, can be assigned to the application "heating of fluid streams" representing $40 \%$ of the identified processes. The application "heating of baths/vessels" also has a major share of $35 \%$. Within the SOPRO project three "priority applications" were determined, which are "cleaning/washing". "heating of baths/vessels" and "drying". In this paper "Cleaning/washing" is considered part of the application "heating of fluid streams" as the basic principle of heating water for washing or make-up water for a steam boiler is the same. Furthermore "drying" is considered as a application, due to the reasons explained above. Beside the analysis of the suitable processes, their temperature level was documented as Figure 3 shows. The importance of low and medium temperature processes shown in Figure 1 can be verified with these results (SOPRO, 2010).

\section{Selected collector types for process heat applications}

In contrast to DHW applications, the temperatures at which process heat applications take place vary significantly. As Figure 1 shows the processes which were identified as promising for the integration of solar heat have set temperatures between $20{ }^{\circ} \mathrm{C}$ to more than $200{ }^{\circ} \mathrm{C}$. As this paper only covers stationary collectors, the temperature range for the simulations was limited to processes between $20 . .120{ }^{\circ} \mathrm{C}$. Following collector types were used for the simulations:

- $\quad$ Flat-plate collector (FPC)

- Double-covered flat-plate collector (FPC-DG)

- $\quad$ Evacuated tube collector (ETC)

- $\quad$ Evacuated tube collector with flat reflector (ETC-FR)

- $\quad$ Evacuated tube collector with CPC-reflector (ETC-CPC)

Table 1 shows the collector parameters for each collector type used in the simulations. $\eta_{0}$ is the optical efficiency, $a_{1}$ the linear and $a_{2}$ the quadratic heat loss coefficients. Typical values were chosen for each collector type from different manufactures. Figure 4 shows the corresponding efficiency curves.

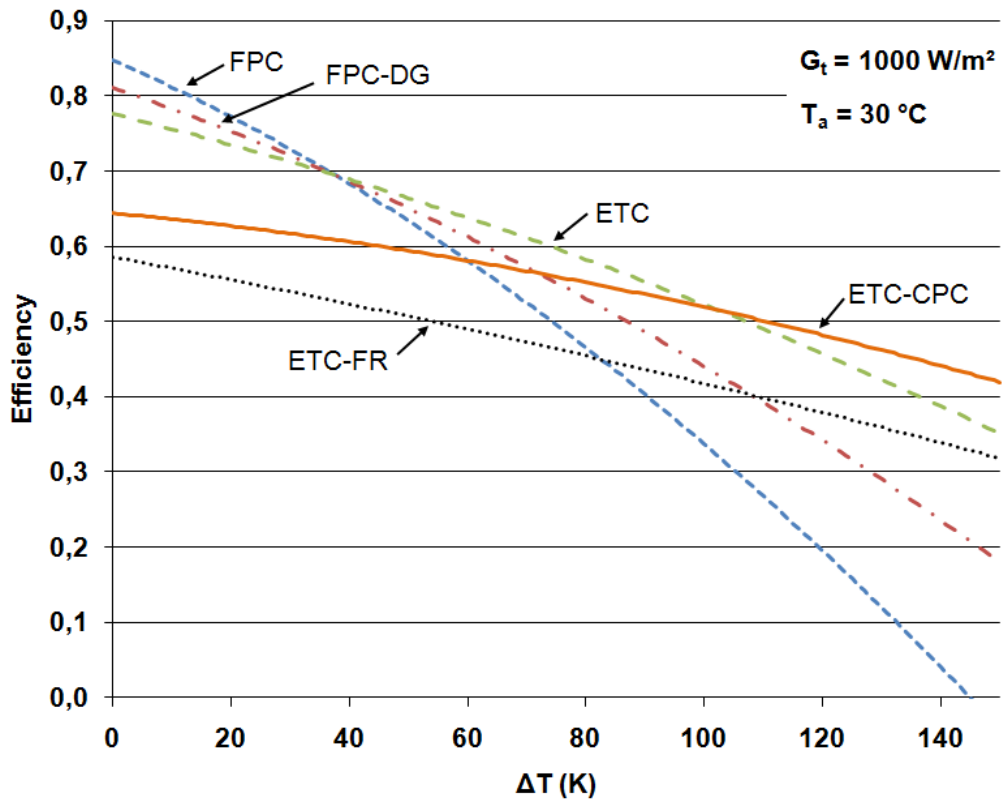

Tab. 1: Collector parameters for each collector type used in the simulations

\begin{tabular}{|l|c|c|c|}
\hline Collector type & $\boldsymbol{\eta}_{\mathbf{0}}(-)$ & $\begin{array}{c}\mathbf{a}_{1} \\
\left(\mathrm{~W} / \mathrm{m}^{2} \mathrm{~K}\right)\end{array}$ & $\begin{array}{c}\mathbf{a}_{2} \\
\left(\mathrm{~W} / \mathrm{m}^{2} \mathrm{~K}^{2}\right)\end{array}$ \\
\hline FPC & 0.848 & 3.460 & 0.017 \\
\hline FPC-DG & 0.811 & 2.710 & 0.010 \\
\hline ETC & 0.776 & 1.936 & 0.006 \\
\hline ETC-FR & 0.586 & 1.485 & 0.002 \\
\hline ETC-CPC & 0.644 & 0.749 & 0.005 \\
\hline
\end{tabular}

Fig. 4: Efficiency curves for each collector type used in the simulations

As shown in Figure 4, at low temperatures the efficiency of FPC, FPC-DG and ETC is significantly higher than the efficiency of ETC-FR and ET-CPC. At medium temperatures the efficiency of the collector types is very similar. Just the evacuated tube collector with flat reflector has a significantly efficiency due to the fact 
that efficiency parameters are determined at normal incidence and the efficiency of evacuated tube collectors with flat reflectors is especially low for a normal incidence angle. E.g. at $15^{\circ}$ incidence angle the optical efficiency rises to 0.749 . For high temperatures the efficiency of FPCs drops strongly, whereas ETCs are still reasonably efficient. Overall, considering the efficiency curves for the selected collector types is not sufficient for the choice of an appropriate collector type for a certain temperature level or solar process heat application.

\section{Simulation model and results}

To determine the annual specific energy yields for the application "heating of fluid streams" various simulations were done for three locations in Europe: Madrid, Stockholm and Würzburg (Germany). Table 2 shows the annual global and direct irradiation and the average ambient temperature at these locations.

Tab. 2: Metrological data for the selected locations

\begin{tabular}{|l|c|c|c|}
\hline Location & $\begin{array}{c}\text { Global irradiation } \\
\left(\mathrm{kWh} / \mathrm{m}^{2} \mathrm{a}\right)\end{array}$ & $\begin{array}{c}\text { Direct irradiation } \\
\left(\mathrm{kWh} / \mathrm{m}^{2} \mathrm{a}\right)\end{array}$ & $\begin{array}{c}\text { Average am bient } \\
\text { tem perature }(\mathrm{C})\end{array}$ \\
\hline Stockholm & 981 & 477 & 7 \\
\hline Würzburg & 1091 & 486 & 9 \\
\hline Madrid & 1662 & 1008 & 16 \\
\hline
\end{tabular}

Figure 5 shows the configuration of the system model for the application "heating of fluid streams". It is assumed that the heat demand of the process is always higher than the heat generation by the solar heating system.

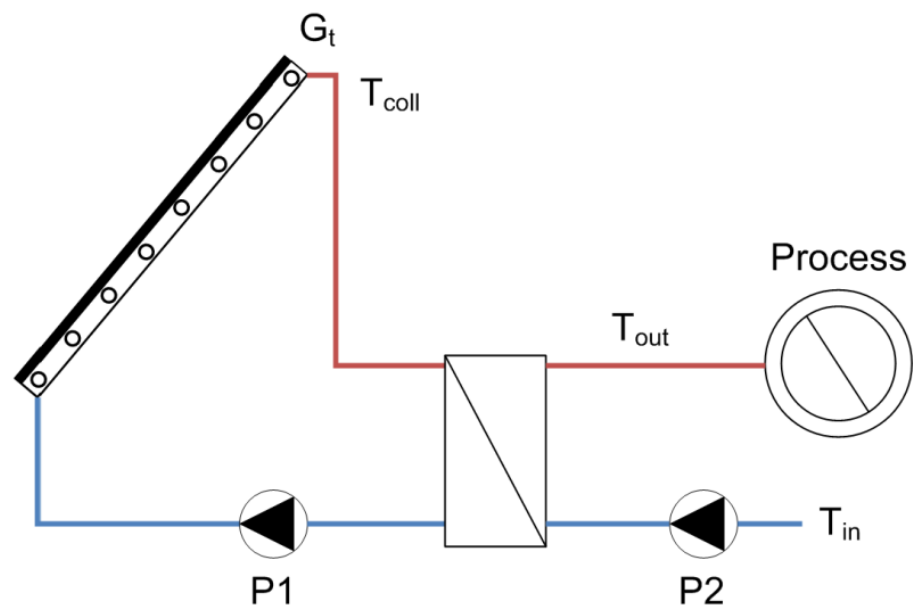

Fig. 5: System configuration for "heating of fluid streams"

An open process is modeled as the secondary loop has an inlet Temperature $\left(T_{\text {in }}\right)$ which is independent of the temperature of the process. Besides heating of cold water $\left(\mathrm{T}_{\mathrm{in}}=20^{\circ} \mathrm{C}\right)$ higher inlet temperatures are considered which often occur due to preheating by heat recovery. Water-glycol $\left(\mathrm{c}_{\mathrm{p}}=3,819 \mathrm{~kJ} / \mathrm{kgK}\right)$ is used in the primary loop which is operated with a specific mass flow rate of $\dot{m}_{\mathrm{p}}=15 \mathrm{~kg} / \mathrm{m}^{2}$ col (related to aperture area of the collector). In the secondary loop water with a mass flow rate which results in equal capacity flows $\left(\dot{\mathrm{C}}_{\mathrm{p}}=\dot{\mathrm{C}}_{\mathrm{s}}\right)$ is used. The heat exchanger has a specific heat transfer coefficient of ua $=100 \mathrm{~W} / \mathrm{Km}^{2}{ }_{\text {col }}$. The pump of the primary loop (P1) is controlled by the total irradiation on the tilted surface $\mathrm{G}_{\mathrm{t}}$ (Madrid $=30^{\circ}$, Würzburg $=40^{\circ}$, Stockholm $=50^{\circ}$ ). If $\mathrm{G}_{\mathrm{t}}>200 \mathrm{~W} / \mathrm{m}^{2}$ the pump P1 is switched on. The secondary pump P2 is controlled by the temperature difference between collector temperature $\left(\mathrm{T}_{\mathrm{col}}\right)$ and the inlet temperature $\left(T_{\text {in }}\right)$. If $T_{\text {col }} \geq T_{\text {in }}+7 \mathrm{~K}$ the pump is switched on and if $T_{\text {col }} \leq T_{\text {in }}+3 \mathrm{~K}$ it is switched off. Figure 6 shows the annual specific energy yield for the system "heating of fluid streams" for Madrid, Würzburg and Stockholm. As expected the results vary substantially between the locations. The annual specific energy yields in Madrid 
are nearly twice as high as the ones in Stockholm. In all locations the system with FPC achieves good results for low inlet temperatures. As the FPC-DG only have a slightly lower optical efficiency compared to FPC this collector type achieves a higher annual specific energy yield already at low inlet temperatures in the secondary loop $\left(\mathrm{T}_{\text {in }}\right)$. Likewise the ETC achieves high annual specific energy yields due to the fact that it is constructed with a single pipe with a vacuum inside. This leads to a very high optical efficiency of 0.776 .
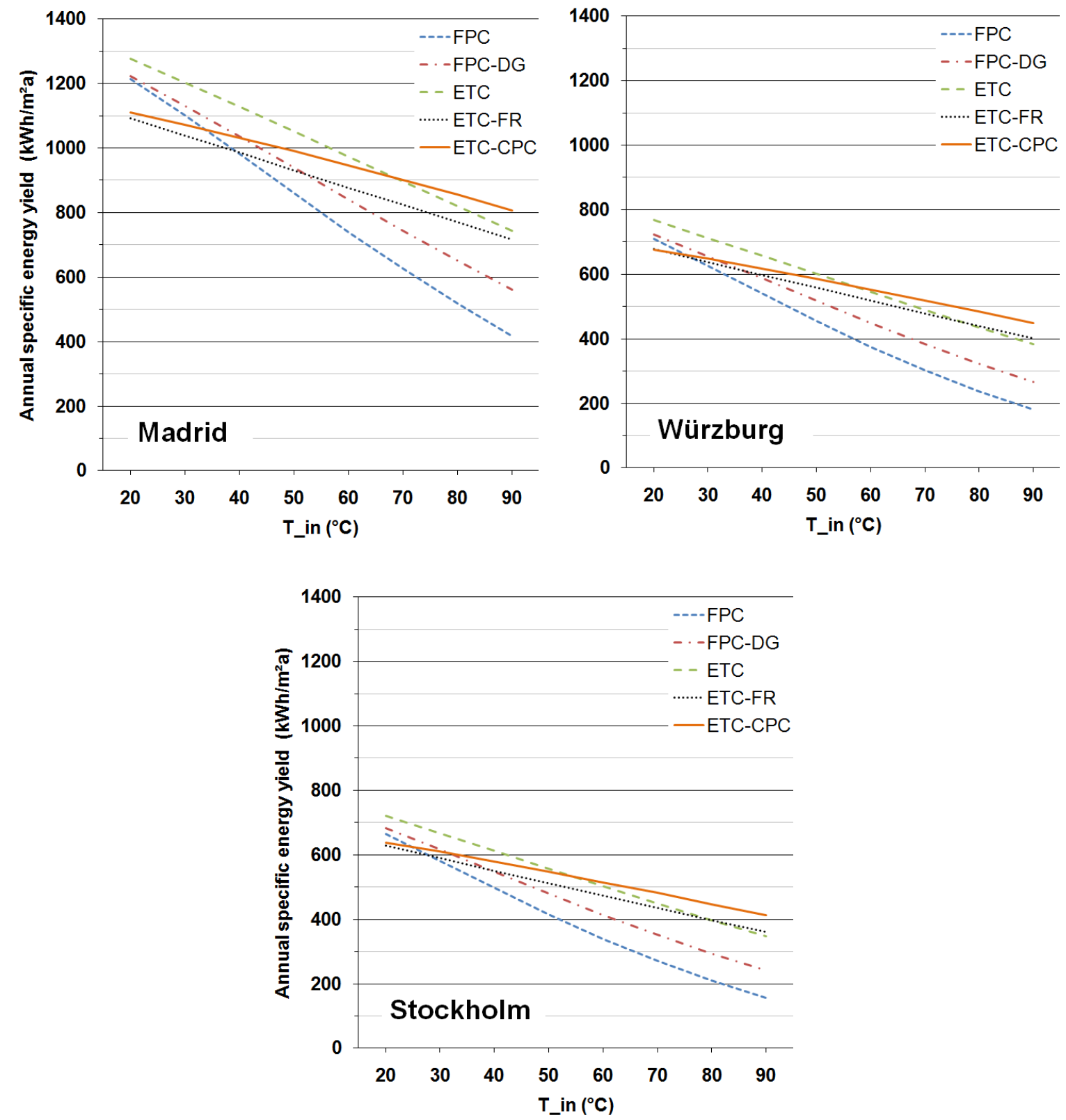

Fig. 6: Annual specific energy yield (related to aperture area of collector) for the system "heating of fluid streams" in Madrid, Würzburg and Stockholm

The utilization of an ETC-CPC delivers higher annual specific energy yields compared to an ETC in Stockholm from $\mathrm{T}_{\text {in }} \geq 60{ }^{\circ} \mathrm{C}$, compared to $70{ }^{\circ} \mathrm{C}$ in Madrid. The energy yields of the ETC-FR do not exceed the one of an ETC because its aperture area is much larger. The extent of additional yield depends on the location. It is important to point out, that the achieved energy yields of the modeled system are higher than for real systems, because of the assumption that the heat demand of the process is always higher than the heat generation by the solar heating system. Although a tendency for the choice of a collector technology can be derived from the results shown in Figure 6, a clear decision for or against a collector technology is hardly possible. Therefore the solar system costs have to be considered for the determination of the suitable collector type and feasibility assessment of a solar process heat application. 


\section{Economical analysis and feasibility assessment}

As shown in the previous chapter, the costs of the solar heating system have to be considered in addition to the annual specific energy yield for the feasibility assessment of a solar heating system in industry. These costs are determined in the first part of this chapter, followed by the calculation of solar heat generation costs and feasibility assessment.

\subsection{Solar system costs}

The collector costs have the largest share of the solar system costs with about $30 \%$ (Remmers, 2001). The prices of several manufactures were analyzed to determine the collector costs for the selected collector technologies considering discounts for collector fields with an aperture area of $500 \mathrm{~m}^{2}$ like it is common for solar process heat applications. These costs were checked with the collector costs listed in (Remmers, 2001). The average costs of installed solar heating systems for the additional components besides the collector were taken from (Peuser et al, 2009) for the above mentioned collector field size. These costs are based on solar heating systems that were built within the funding program "Solarthermie2000" of the German Federal Ministry for the Environment. Value added tax is deducted in case a company purchases a solar heating system, so it is not considered in this calculation. Table 3 shows the specific investment costs for the selected collector field size.

Tab. 3: Collector costs for selected collector types and collector field sizes of $500 \mathbf{~ m}^{2}$ (aperture area)

\begin{tabular}{|l|c|}
\hline Collector type & System costs $\left(\boldsymbol{\epsilon} / \mathbf{m}^{\mathbf{2}}\right)$ \\
\hline FPC & 443 \\
\hline FPC-DG & 466 \\
\hline ETC & 641 \\
\hline ETC-FR & 558 \\
\hline ETC-CPC & 603 \\
\hline
\end{tabular}

As Table 3 shows, the specific system costs of the solar heating system are significantly lower for a FPC than for ETC. The costs for ETC-FR are lower than for the other ETCs because of the simple construction and large resulting aperture area. For the calculation of the solar heat generation costs no subsidy for the system costs was considered. On the one hand this is done for better comparability, on the other hand the calculated annual specific energy yields are quite high because of the assumption that all generated heat is consumed.

\subsection{Solar heat generation costs and feasibility assessment}

The feasibility for the solar process heat application "heating of fluid streams" is assessed by combining simulation results with the cost analysis performed in the last subchapter to calculate solar heat generation costs $\left(\mathrm{k}_{\mathrm{SOL}}\right)$ for this applications. The calculation of the solar heat generation costs only takes into account the additional investment for the solar heating system, which are capital-related $\left(\mathrm{k}_{\mathrm{INV}}\right)$, operational $\left(\mathrm{k}_{\mathrm{BETR}}\right)$ and consumption-related ( $\mathrm{k}_{\mathrm{VERBR}}$ ) costs in this simplified calculation (VDI, 2004). $\mathrm{f}_{\mathrm{a}}$ represents the annuity factor.

$\mathrm{k}_{\mathrm{SOL}}=\frac{\mathrm{k}_{\mathrm{INV}} \cdot \mathrm{f}_{\mathrm{a}}+\mathrm{k}_{\mathrm{BETR}}}{\mathrm{Q}_{\mathrm{SOL}}}+\mathrm{k}_{\mathrm{VERBR}}$

For the calculation of the solar heat generation costs a service life of 20 years was considered, as (VDI, 2004) suggests. Furthermore, a capital interest rate and increase of energy prices of $5 \%$, maintenance cost of $1 \%$ of investment costs and a price for electricity of $11 €-C e n t / \mathrm{kWh}_{\mathrm{el}}$ was assumed.

Figure 7 shows solar heat generation costs for the solar process heat application "heating of fluid streams" in dependence of inlet temperature of the secondary loop $\left(\mathrm{T}_{\mathrm{in}}\right)$ for Madrid, Würzburg and Stockholm for a collector field size (aperture area) of $500 \mathrm{~m}^{2}$. Just as the annual specific energy yield, the solar heat generation costs depend strongly on the location. The lowest costs can be achieved in Madrid for preheating 
cold water $\left(\mathrm{T}_{\text {in }}=20{ }^{\circ} \mathrm{C}\right)$ with about $3.5 €$-Cent $/ \mathrm{kWh}$. The costs rise for applications with $\mathrm{T}_{\text {in }}=90{ }^{\circ} \mathrm{C}$ to $6.5 €$-Cent $/ \mathrm{kWh}$ using ETC-CPC. For Würzburg the corresponding costs are 6 and $12 €$-Cent $/ \mathrm{kWh}$, while for Stockholm a little more than $6 €$-Cent $/ \mathrm{kWh}$ can be achieved with FPCs for preheating at $\mathrm{T}_{\text {in }}=20^{\circ} \mathrm{C}$ and $13 €$-Cent $/ \mathrm{kWh}$ at $\mathrm{T}_{\text {in }}=90^{\circ} \mathrm{C}$, using ETC-CPC
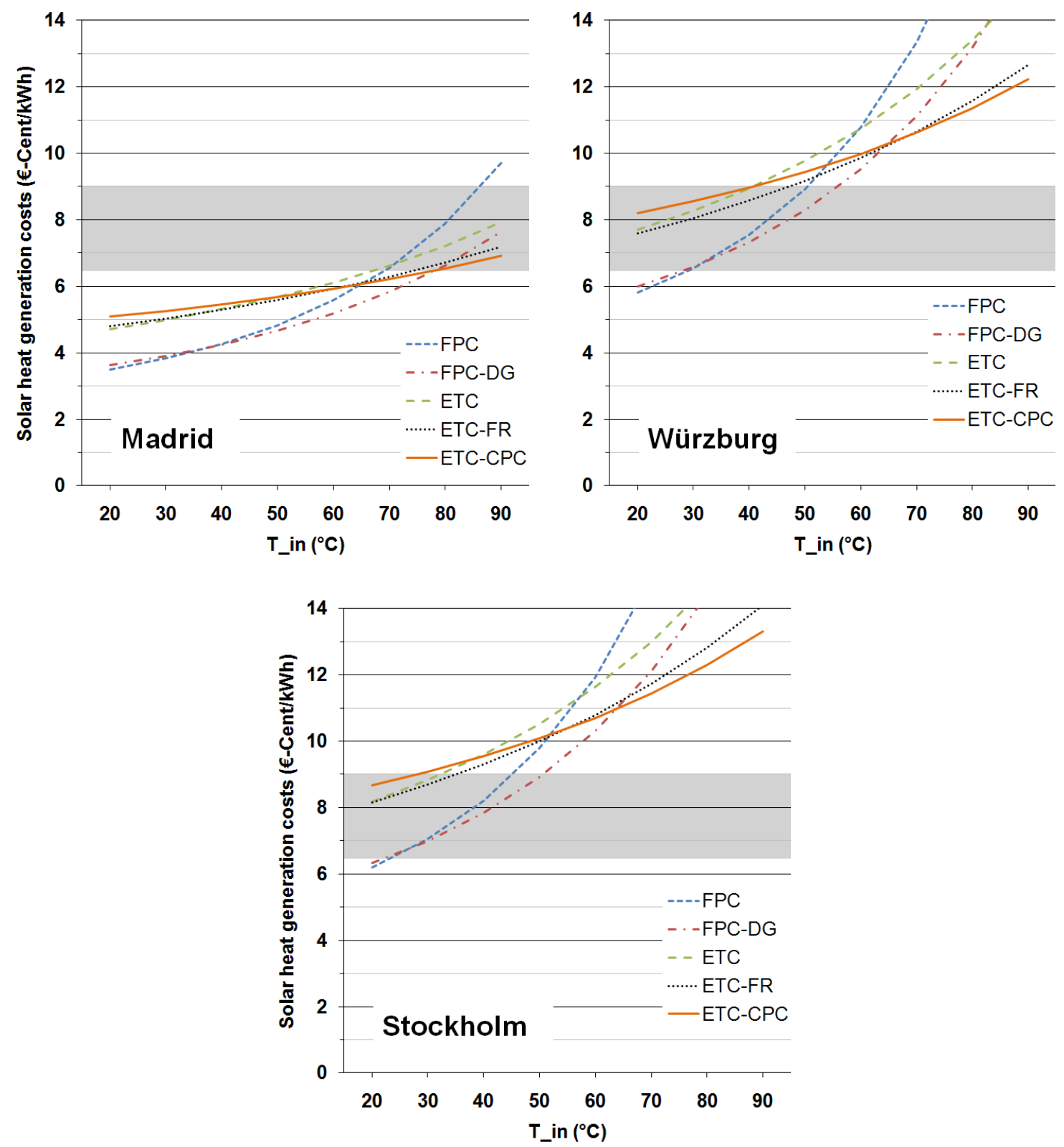

Fig. 7: Solar heat generation costs for the system "heating of fluid streams" in Madrid, Würzburg and Stockholm. The grey box represents the conventional heat generation costs

Recommendations for the use of collector types for different system inlet temperatures $T_{\text {in }}$ can be given considering the results presented in Figure 7. For inlet temperatures below $60{ }^{\circ} \mathrm{C}$ using FPC or FPC-DG provides the lowest solar heat generation costs. For Madrid there is hardly a difference of the solar heat generation costs up to $50{ }^{\circ} \mathrm{C}$ using FPC or FPC-DG. At inlet temperatures higher than about $70{ }^{\circ} \mathrm{C}$ (or slightly higher for Madrid) ETC-FR and ETC-CPC are economically more feasible than FPCs. ETCs without a reflector never achieve the lowest solar heat generation costs.

To judge about the feasibility of a selected application the solar heat generation costs have to be compared with the heat prices of conventional heat generation technologies. In (Lauterbach et al., 2011a) the gas prices for industrial companies and their development in the past were analyzed. The price for gas, which is the mostly used fossil fuel in industry, is in the range of $3 . .4 €$-Cent $/ \mathrm{kWh}$ depending on the size of the company. 
These costs lead to conventional heat generation costs in the range of $6.5 .9 €$-Cent/kWh, as displayed in Figure 7. A capital interest rate of $5 \%$, an increase of energy prices of $5 \%$ and an average boiler and heat distribution efficiency of $75 \%$ was assumed.

Figure 7 shows that the use of solar heating systems in industry is feasible for all inlet temperatures in Madrid, as lower solar heat generation costs can be achieved with different collector types compared to conventional heat generation costs. For Würzburg solar process heat applications with inlet temperatures below $60{ }^{\circ} \mathrm{C}$ are economically feasible, respectively for $\mathrm{T}_{\text {in }}<50{ }^{\circ} \mathrm{C}$ in Stockholm.

\section{Summary and Outlook}

The analysis of industrial processes shows that similar applications for solar process heat exist across several sectors. Therefore, industrial processes were categorized, which facilitates the identification of typical applications for solar process heat. The three major applications are "heating of fluid streams", "heating of baths/vessels" and "drying". Further possibilities to integrate solar heat exist in the heat supply level of an industrial company. The feasibility for a major solar process heat application, the "heating of fluid streams", was assessed by combining simulation results with a cost analysis of solar heating system using different collector types and fossil fuel prices. This assessment was done for different regions.

It was found, that for inlet temperatures below $60{ }^{\circ} \mathrm{C}$ using flat-plate or double-covered flat-plate collectors provides the lowest solar heat generation costs and at inlet temperatures higher than about $70{ }^{\circ} \mathrm{C}$ evacuated tube collectors with flat or CPC reflector are economically more feasible. The use of solar heating systems in industry is feasible for all investigated inlet temperatures in Madrid. For Würzburg solar process heat applications with inlet temperatures below $60{ }^{\circ} \mathrm{C}$ are economically feasible, respectively for $\mathrm{T}_{\text {in }}<50{ }^{\circ} \mathrm{C}$ in Stockholm.

Additional investigations are necessary for the other solar process heat applications, not covered in this paper as well as applications on heat supply level. Furthermore, the determination of annual specific energy yields has to be performed for different industrial load profiles and methodology for a fast and simple estimation of losses within the solar heating system has to be developed.

\section{References}

Aidonis, A., Drosou, V., Mueller, T., Staudacher, L., Fernandez-Llebrez, F., Oikonomou, A., Spencer, S., 2002. PROCESOL II - Solar thermal plants in industrial processes. Center for Renewable Energy Sources. Pikermi, Greece.

Lauterbach, C., Schmitt, B., Jordan, U., Vajen, K., 2010. Potential for Solar Process Heat in Germany Suitable Industrial Sectors and Processes. Proc. EuroSun. Graz.

C. Lauterbach, B. Schmitt, U. Jordan, K. Vajen. 2011a: Solare Prozesswärme in Deutschland - Potential und Markterschließung. 21. Symposium Thermische Solarenergie. Bad Staffelstein

Lauterbach, C., Schmitt, B., Vajen, K., Jordan, U., 2011b. Das Potential Solarer Prozesswärme in Deutschland. Universität Kassel.

Müller, T., Weiß, W., Schnitzer, H., Brunner, C., Begander, U., Themel, O., 2004. PROMISE - Produzieren mit Sonnenenergie. Bundesministerium für Verkehr, Innovation und Technologie. Wien.

Peuser, F.A., Croy, R., Mies, M., Rehrmann, U., Wirth, H.P., 2009. Solarthermie-2000, Teilprogramm 2 und Solarthermie2000plus - Wissenschaftlich-technische Programmbegleitung und Messprogramm (Phase 3). ZfS - Rationelle Energietechnik GmbH, Hilden

Remmers, K.-H., 2001. Große Solaranlagen - Einstieg in Planung und Praxis. Solarpraxis, Berlin

Schmitt, B. Lauterbach, C., Vajen, K., 2011. Investigation of selected solar process heat applications regarding their technical requirements for system integration. Proceedings Solar World Congress, Kassel.

Schweiger, H., Mendes, J.F., Schwenk, C., Hennecke, K., Barquero, C.G., Sarvisé, A.M., Carvalho, M.J., 2001. POSHIP - The Potential of Solar Heat for Industrial Processes. AIGUASOL Enginyeria. Barcelona. 
SOPRO Project, 2010. WP2- Priority applications selection summary. Downloaded from http://www.solarprocess-heat.eu on 05/08/2011

Vannoni, C., Battisti, R., Drigo S., 2006. SHIP - Plant Survey Report. IEA SHC Task 33/IV, CIEMAT, Madrid.

Vannoni, C., Battisti, R., Drigo S., 2008. Potential for Solar Heat in Industrial Processes. Booklet IEA SHC Task 33/IV, CIEMAT, Madrid.

VDI - Verein Deutscher Ingenieure, 2004. VDI 6002: Solar heating for domestic water - General principles, system technology and use in residential building, Düsseldorf.

VDI - Verein Deutscher Ingenieure, 1996. VDI 6025: Economy calculation systems for capital goods and plants, Düsseldorf.

The authors gratefully acknowledge the financial support provided by the German Federal Ministry for the Environment, Nature Conservation and Nuclear Safety, contract No. 0329601T. 